\title{
Innovations in Pediatric Education at the University of Rwanda, Kabgayi Campus, Rwanda
}

\author{
Sister Domitilla Mukantabana ${ }^{1}$, Yvonne Nsaba Uwera ${ }^{1}$, Christine Igikundiro ${ }^{1}$, Fauste Uwingabire ${ }^{1}$, \\ Patricia Moreland ${ }^{1}$ \\ ${ }^{1}$ Kabgayi School of Nursing and Midwifery
}

\section{Background}

Reducing under- 5 year mortality is a priority for Rwanda and consistent with Millennium Development Goal (MDG) 4; to reduce child mortality by two-thirds by the year 2015. Despite the significant progress made in reducing under-5 mortality over the past five years, Rwanda now faces the challenge of sustaining these gains as morbidity and burden of disease remains high. Achievement of the MDGs and sooner the Sustainable Development Goals (SDGs) will require a scaling-up of nursing and midwifery education and strengthening of the knowledge and skills of health care providers.

\section{Methods}

The objectives of the project were to strengthen the paediatric curriculum by integrating the MDGs and to enhance the capacity of nurses and midwives to contribute to the achievement of the MDGs. In March 2014, the pediatric curriculum was revised using the MDGs as a framework.

\section{Results}

The revised curriculum focused on common causes of mortality in children including pneumonia, diarrhea, malaria, measles, malnutrition, HIV/AIDS, poverty, and maternal health. Integrating the MDGs into the pediatric curriculum provided a format to evaluate the achievements and challenges facing Rwanda. Students were able to associate the achievement of the MDGs with their individual district or village.

\section{Conclusion}

The contribution of nurses and midwives to the achievement of the MDGs and their success or SDGs should be emphasized in all courses.

Key words: MDGs, under-5 mortality, nursing, midwifery, education 